\title{
The Impact of Online Live Broadcasting on Consumer Online Shopping Decision: From the Perspective of Behavioral Economics
}

\author{
Huang zhanbing, Zhang bin* \\ International Business School, Shaanxi Normal University \\ Xi'an 710119, P. R. China \\ zbwyyx@163.com
}

\begin{abstract}
In the traditional online shopping mode, consumers expense a lot of mental cost in order to get enough commodity information, which leads to the decline of consumer shopping utility. The online live broadcasting mode improves the shortterm utility of consumer shopping by reducing the mental cost of searching for commodity information and enhancing the visceral factors of consumers. Based on the behavioral economics theory, this paper analyzes the consumer purchase preference by adding the mental cost and visceral factors into the consumer utility function, and establishes the agent-based simulation model to study the interaction between the mental cost and the visceral factors through simulation experiments. Both mental cost and visceral factors have significant influence on consumer purchase rate, but mental cost has more influence on consumers' online shopping choice than visceral factors. Increasing commodity Information acquisition Speed can significantly increase the rate of consumer purchases.
\end{abstract}

Keywords-Behavioral economics; Online live broadcasting; Consumer decision-making; Mental cost; Visceral factors

\section{INTRODUCTION}

Since entering the era of mobile Internet, online shopping has become more convenient and universal. It becomes more difficult for consumers to choose the suitable commodities as the wide variety of commodities and complex promotional activities. Under the traditional online shopping mode, in order to get enough commodity information, consumers need to read a large number of online reviews to determine whether the goods match the publicity, in addition to checking the pictures and words displayed by the online stores. For the details of the goods and the actual use of the effect, consumers also need to communicate online with the store. The process of searching for commodity informations and analyzing sales promotion rules will not only expense a lot of time, but also expense a large amount of mental cost of consumers, which will lead to the reduction of consumer shopping utility. If the mental cost of consumption is too high, consumers will give up shopping.

In recent years, online shopping platforms have grown rapidly in China, Taobao and JingDong, the two largest online shopping platforms, both having their own online video live shopping sections. In online live broadcasting model, shopping anchor or shopkeeper can directly display the commodities to the online audience through video, and can communicate with the audience immediately and answer the audience's doubts. This new sales model allows consumers to learn more quickly and fully about commodity informations.

Compared with traditional graphic-text mode, the online live broadcasting mode greatly reduces consumer's mental cost and improves shopping experience. the online live broadcasting mode promotes more direct interaction between sellers and consumers, as well as consumers and consumers, which then makes the consumer's immediate emotion easy to be influenced by the gorgeous appearance of the goods and other consumers' purchase behavior, thus overestimating the utility of the commodity itself and producing irrational behavior of impulsive purchase. From the perspective of behavioral economics, this paper analyzes how online broadcast mode affects consumers' preferences and changes their purchasing behavior. Agentbased simulation model is established to analyze the interaction between mental cost and instinct factors on consumer purchase behavior.

\section{THEORETICAL ANALYSIS OF THE INFLUENCE OF ONLINE LIVE BROADCASTING ON CONSUMER BEHAVIOR}

\section{1) Related behavioral economics theory}

a) Two Systems and commodity information search cost

Behavioral economist Kahnemann (2011) [1] points out that when people make choices, there are two different systems in the brain: one is the "system 1" that works quickly and automatically, and the other is the "system 2", which runs more slowly and logically. System 1 is subconscious, which is influenced by habit and emotion, and the operation of System 2 is controlled deliberately, which requires a lot of energy. The massive operation of System 2 will increase people's cognitive load and reduce their cognitive ability and executive control ability (Mullainathan \& Shafir, 2013) [2].

The process of searching for commodity information, reviewing reviews and analyzing the rules of promotion in a complex web page requires the continuous operation of the System 2, which will consume a lot of energy and make the consumer feel tired. The mental cost of excessive operation of System 2 not only reduces the consumer's shopping experience, but also affects the consumer's choice efficiency, Ultimately, the utility of purchasing commodity is reduced, and even gives up buying. 
Online live broadcasting not only increases the shopping experience of consumers, but also reduces the time cost and mental cost for consumers to search for commodity information. Intuitive visual effects and instant interaction allow consumers to reduce the operation of System 2 during the shopping process, a lot of information can be obtained by the System 1 . Therefore, compared with the traditional graphic-text mode, the online live broadcasting mode reduces the mental cost of consumers and increases the utility of purchasing commodity.

\section{b) visceral factors and impulse purchase}

Behavioral economist George Loewenstein points out that visceral factors have an impact on human preferences (Loewenstein, 1996) [3]. The visceral factors include emotions caused by mood and physiological driving factors. When the intensity of visceral factors is strong enough, it will affect the attention, consciousness and impulsiveness of human beings. The strengthening of the visceral factors caused by immediate emotions leads to the loss of control over one's own behavior, and it is easier to make impulsive behaviors. The change of visceral factors will change the ability of people to process information and make rational decisions (Loewenstein et al., 2003) [4].

Loewenstein et al. (1998) [5] proposed the "hot-cold empathy gaps". People in a cold visceral state will underestimate the effect of hot state on themselves and thus underestimate their likelihood of impulsive behavior in a hot state. While people in hot state will underestimate the influence of emotional state on their preferences and behavioral tendencies, which leads them to overestimate the reliability and stability of their current preferences and make short-term preference choices. Compared with the traditional graphic-text mode, consumers' interest in commodity is more likely to be boosted by visual video display and interactive propaganda in the online live broadcasting mode. Seeing other people's purchase behavior in the live broadcasting will further stimulate their desire to buy. When consumers' immediate emotions are changed by these factors, consumers are in a hot visceral state, which increases the short-term utility of commodity to consumers.

\section{2) Utility model}

\section{a) Model establishment}

Based on the research of Loewenstein (2000) [6]. this paper adds mental cost and instinctive factors to the consumer utility model. The consumer utility function is as follows:

$$
\begin{gathered}
u=v\left(x_{i}, m, s, c\right) \\
\frac{\partial v\left(x_{i}, m, s, c\right)}{\partial s}>0, \frac{\partial^{2} v\left(x_{i}, m, s, c\right)}{\partial x_{i} \partial s}>0 \\
\frac{\partial v\left(x_{i}, m, s, c\right)}{\partial c}<0, \frac{\partial^{2} v\left(x_{i}, m, s, c\right)}{\partial x_{i} \partial c}<0
\end{gathered}
$$

Where $x_{i}$ is the amount of commodity $i$ that consumers buy. $m$ represents consumer consumption on other commodities. $s$ is visceral state of consumer; $c$ is the mental cost to search for information on commodity i. Eq. 2 indicates that the marginal utility of commodity $i$ increases with an increase in the visceral factor $s$, Eq. 3 indicates that the marginal utility of commodity I decreases as the mental cost $c$ increases.

\section{b) The effect of emotion on consumer utility}

Figure 1 shows the Indifference curve of consumer utility, Assuming consumer utility in cold visceral state $v\left(0, m_{0}, s_{c}, c\right)>v\left(x_{i}^{*}, m^{*}, s_{c}, c\right)$, When consumers watch live sales of commodity $i$, the visceral factors boost and the marginal utility of commodity $\mathrm{i}$ increases, there is $v\left(0, m_{0}, s_{h}, c\right)<v\left(x_{i}^{*}, m^{*}, s_{h}, c\right)$. The utility of consumer in cold state at B points is higher than A points, so he choose not to buy commodity I; when in hot stae the consumer has a higher utility at point $\mathrm{A}$ than point $\mathrm{B}$, and the consumer choose to buy。

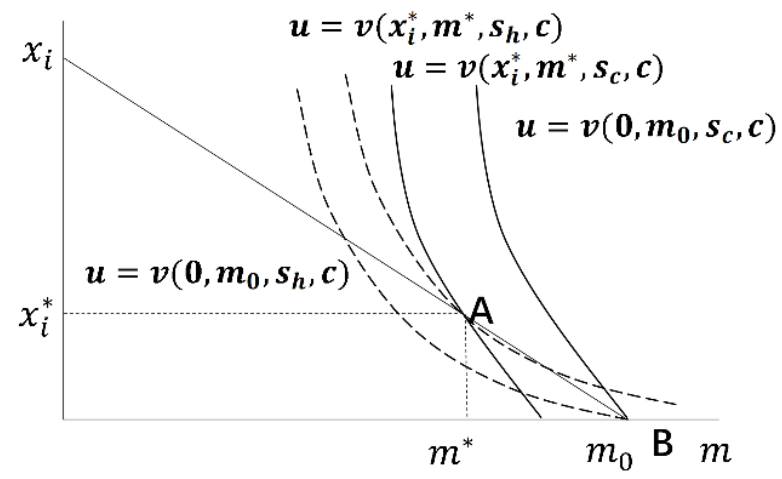

Fig. 1 Indifference curve of consumer utility

\section{c) The effect of mental cost on consumer utility}

Consumers make purchasing decisions based on the information they get about the commodity. Suppose consumer needs to get no less than $z_{i}^{*}$ commodity information before he buy it. Consumer utility and its marginal utility decrease as the cost of mental cost increases the utility of the commodity i itself to the consumer is $u_{i}$. In the traditional graphic-text mode, consumers need to expense mental cost $c_{3}$ to obtain the information $z_{i}^{*}$, and the consumer utility after buying the commodity i is $v\left(x_{i}^{*}, m^{*}, s, c_{3}\right)<0$, so the consumer chooses not to buy it, In online live broadcasting mode, the consumer only needs to expense mental cost $c_{1}$ to get information $z_{i}^{*}$. The consumer utility after buying the commodity $i$ is $v\left(x_{i}^{*}, m^{*}, s, c_{1}\right)$; At this time there is $v\left(x_{i}^{*}, m^{*}, s, c_{1}\right)>0>v\left(x_{i}^{*}, m^{*}, s, c_{3}\right)$, the consumer chooses to buy it. The online live broadcasting mode improves the uility of consumer shopping by reducing consumers' mental cost to search for merchandise information.

Suppose that the mental cost that consumers have already spent in the traditional graphic-text mode is $c_{2}$, consumer utility is $v\left(0, m_{0}, s, c_{2}\right)<0$, Corresponding to point $\mathrm{F}^{\prime}$ in Figure 2; If the consumer continue to search for information, when his mental cost reaches $c_{3}$, the consumer utility is $G^{\prime}$ in Figure 2. If the consumer chooses to buy commodity $\mathrm{i}$, the utility is $v\left(x_{i}^{*}, m^{*}, s, c_{3}\right)$, Corresponding to point $\mathrm{G}^{\prime \prime}$, the consumer's utility at the point $G^{\prime \prime}$ is lower than that at the point $F^{\prime}$. As a result, the consumer will choose to give up buying after they have spent $c_{2}$ mental cost. 


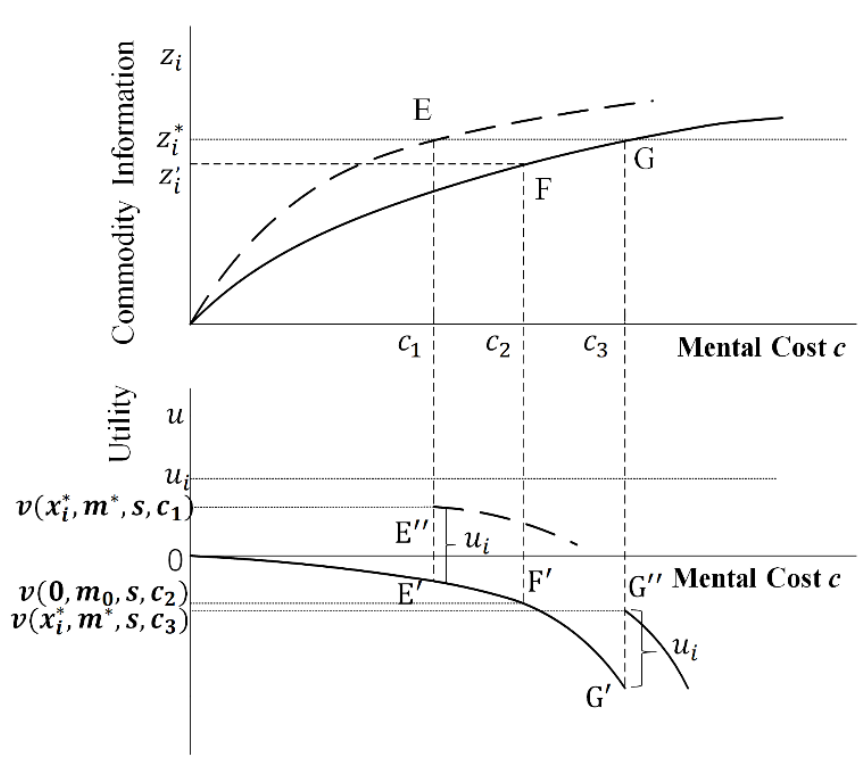

Fig. 2 Commodity Information and Consumer Utility

\section{AGENT-BASED SIMULATION MODEL OF CONSUMER PURCHASE DECISION-MAKING}

We set up an Agent-based simulation model to analyze the interaction of mental cost and visceral factors on consumers online purchase decision-making. In this model, the same commodity has different purchase value to different consumers. Each agent has different utility values and buying desire for commodity i. Each consumer's visceral factor rate is generated independently and randomly in this model.

Assuming that the marginal mental cost $M C_{j}$ of consumers increases, $\gamma_{c}$ is mental cost growth rate, $C_{j}$ is the total mental cost of consumer $\mathrm{j}$ searching for commodity $\mathrm{i}$ information:

$$
\begin{gathered}
M C_{j}^{k}=M C_{j}^{0}\left(1+\gamma_{c}\right)^{k} \\
C_{j}=\sum_{e=0}^{k} M C_{j}^{e}=\frac{M C_{j}^{0}\left[\left(1+\gamma_{c}\right)^{k}-1\right]}{\gamma_{c}}
\end{gathered}
$$

Assume that the probability that consumers are in a hot visceral state of increases as the amount of information available on the commodity $\mathrm{i}$ increases. When the consumer is in a cold state, $s_{j}=1$. When the consumer is in a hot state, $s_{j}>1, s_{j}=1+$ $\theta_{j}, \theta_{j}$ is hot state rate, $0<\theta_{j}<1$.

The utility function of consumer $\mathrm{j}$ :

$$
u_{j}=v\left(x_{i j}, m_{j}, s_{j}, c_{j}\right)=s_{j} N_{i j} x_{i j}-\rho C_{j} \delta^{C_{j}}
$$

$$
u_{j}=s_{j} N_{i j} x_{i j}-\rho \frac{M C_{j}^{0}\left[\left(1+\gamma_{c}\right)^{k}-1\right]}{\gamma_{c}} \delta \frac{M C_{j}^{0}\left[\left(1+\gamma_{c}\right)^{k}-1\right]}{\gamma_{c}}
$$

Where $s_{j}$ is the visceral factor rate of the consumer $\mathrm{j}, N_{i j}$ is the uility of commodity $\mathrm{i}$ to consumer $\mathrm{j}$ without taking into account mental cost. $\rho, \delta$ are model parameter.

Consumer purchase decision-making rules as shown Eq. 7.

$$
\left\{\begin{array}{lll}
u_{j}<0 & z_{i j}<z_{i}^{*} & \text { Give up buying commodity } i \text { in advance } \\
u_{j}<0 & z_{i j} \geq z_{i}^{*} & \text { Do not buy commodity } i \\
u_{j} \geq 0 & z_{i j} \geq z_{i}^{*} & \text { buy commodity } i
\end{array}\right.
$$

\section{SIMULATION EXPERIMENT AND RESULT ANALYSIS}

We use NetLogo 6.0.3 (Wilensky, 1999) [7] to do simulation experiments, each the experiment group generates 1089 consumers, the utility $N_{i j}$ of each consumer $\mathrm{j}$ to the commodity $i$ itself is an independent and randomly generated integer value between $(0,150)$. The hot state rate $\theta_{j}$ is an independently generated random floating point value between $(0,1)$. Set the threshold of commodity information $z_{i}^{*}$ to be 30 needed when the consumer decides to purchase. After debugging, set the parameters in the model $\mathrm{a}=1.5, \mathrm{~b}=1.005$.

\section{A. Information acquisition speed is fixed}

Under the condition that the information acquisition speed $\alpha_{i}=1$ is fixed, we simulate $\mathrm{d}$ consumer online shopping choices at hot and cold state and different mental cost growth rates $\gamma_{c}$.Setting $\gamma_{c}=\{0.055,0.060,0.065,0.070\}$, respectively tests 20 times without visceral factors and with visceral factors. In Figure 3, the left is shown the statistical results of the ratio of consumers who have given up buying without having found enough commodity information at Time step $=25$. The right side shows the statistical results of the ratio of consumers who finally choose to buy after searching enough commodity information at Time step $=30$, The above statistical results are analyzed by Oneway ANOVA. Whether or not visceral factors were taken into account, the number of people who gave up buying and the number of people who eventually bought at different mental cost growth rates were significantly different at a level of $1 \%$. In order to search for commodity information, excessive expense of mental costs will significantly reduce the purchase rate of commodity. Visceral factors will also significantly affect the final purchasing ratio, but its impact on consumer purchase decision-making is less than the impact of mental cost. 
Time step $=25$
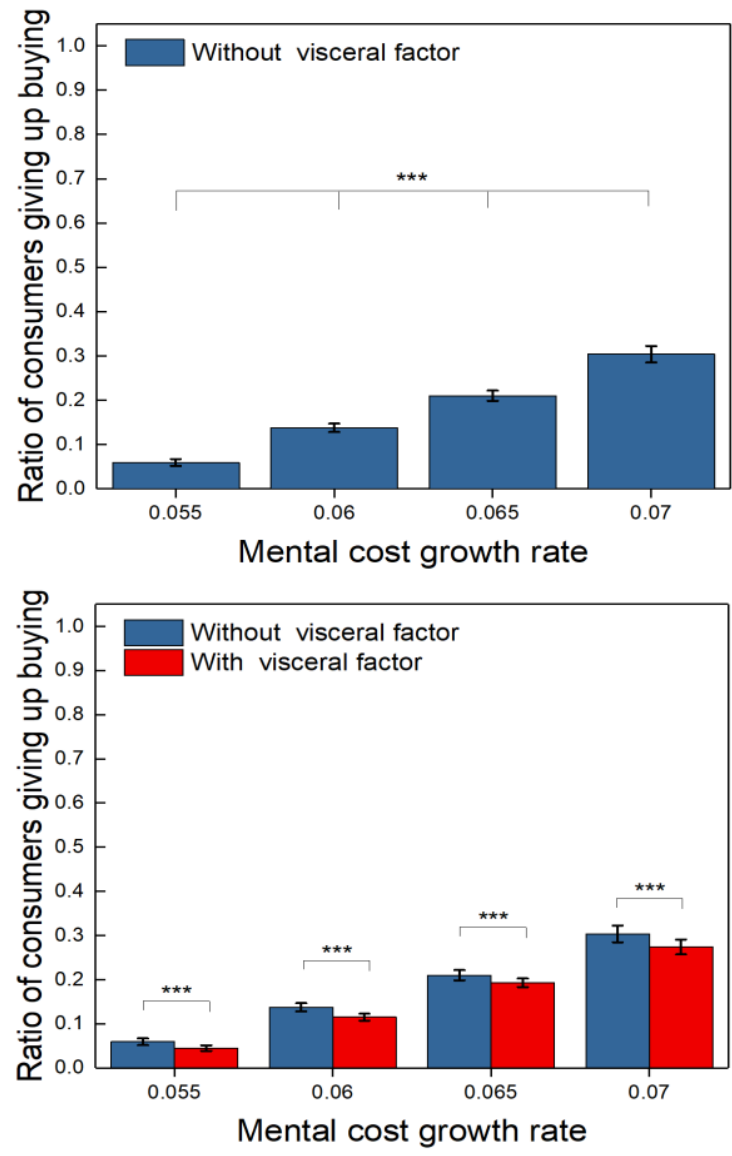

Time step $=30$

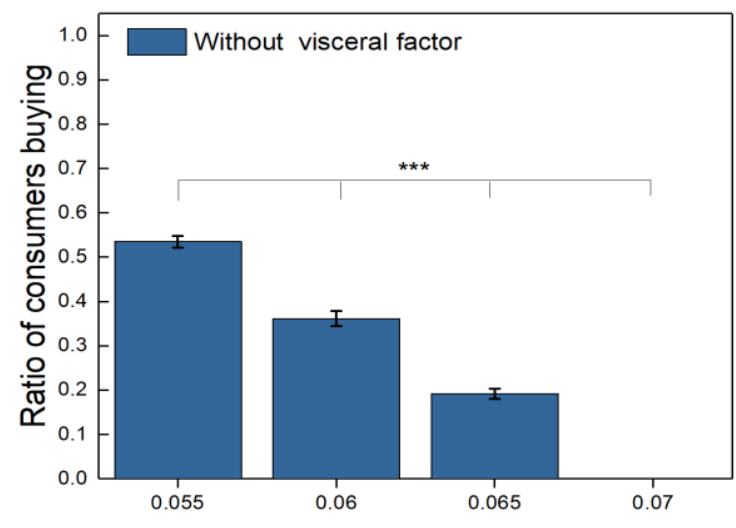

Mental cost growth rate

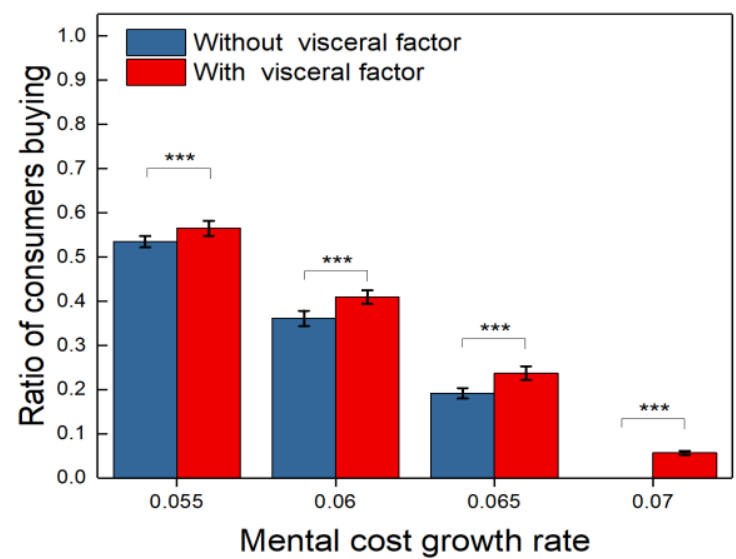

Fig. 3 Influence of mental cost and visceral factor on consumers purchase choice

Note: One-way ANOVA was made for the experimental data between each group, $\quad * * * \mathrm{P}<0.001$

\section{B. Change of information acquisition speed}

To study the impact of information acquisition speed on consumers purchase choices, setting $\alpha_{i}=\{1.0,1.1,1.2,1.3\}$, $\gamma_{c}=\{0.065,0.080\}$, Each combination was repeated 20 times without and without visceral factors, and the results were tested by One-way ANOVA.

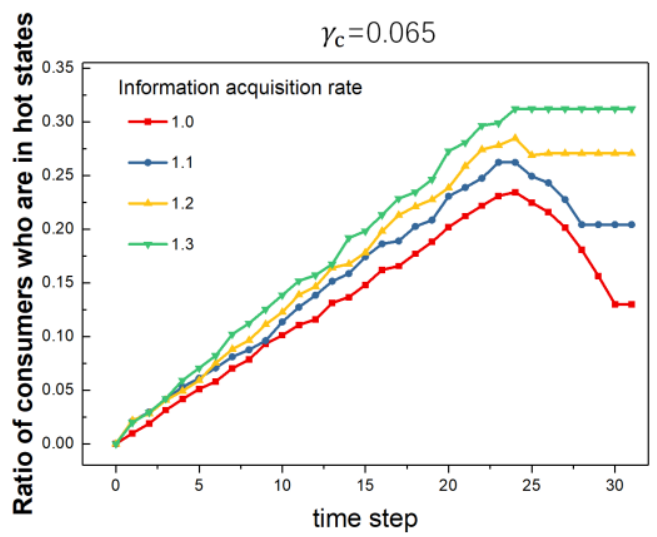

As shown in Figure 4, the ratio of the number of hot states increases first and then decreases, and the number of people in the hot state will begin to decline when the information acquisition speed is slow. In Figure 5, increasing the information acquisition rate can significantly increase the ratio of consumer buying.

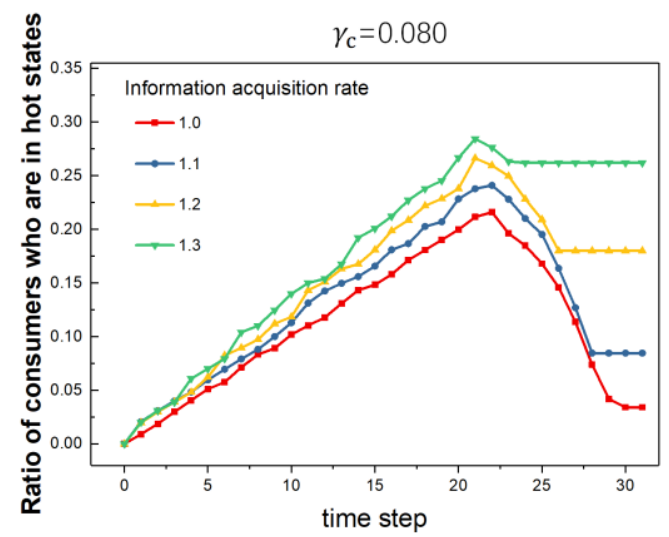

Fig. 4 Changes in Consumer visceral factor 

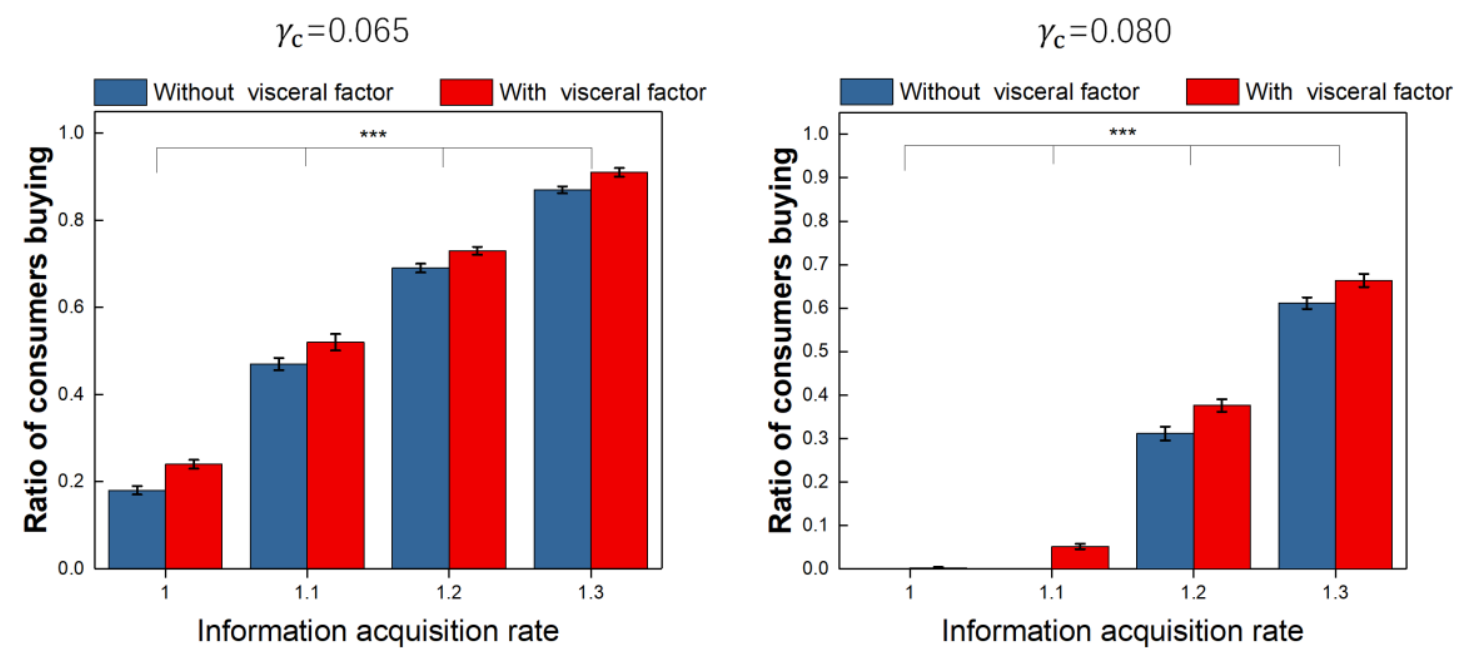

Fig. 5 The influence of Information acquisition Speed on Consumer purchase

Note: One-way ANOVA for experimental data at different information acquisition rate

$* * * \mathrm{P}<0.001$

\section{CONCLUSIONS}

Based on the theory of behavioral economics, this paper analyzes the influence of mental cost and visceral factors on consumers' online shopping decisions. The tedious way of obtaining commodity information and the slow commodity information acquisition Speed make consumers expense too much mental cost to reduce the utility of purchasing commodity eventually, and even make consumers give up buying when they do not get enough commodity information.

In this paper, an Agent-based simulation model is established to analyze the interaction between instinctive factors and mental costs, we found both mental cost and visceral factors can change consumers' purchasing behavior. But the effect of mental cost on consumer purchase behavior is greater than that of visceral factor. Increasing the speed of obtaining commodity information can reduce the mental cost of consumer shopping, and thus significantly increase the consumer purchase ratio.

Compared with the traditional graphic-tex mode, the online live broadcasting mode improves the rate and the efficiency of the consumer to acquire the commodity information, and reduces the mental cost. Meanwhile, online live broadcasting change consumers' immediate emotions and keep consumers in hot visceral state easily. So the online broadcasting improves the short-term utility of consumers to buy commodity.
The conclusion of this paper also needs the verification of the empirical data, and the simulation model also needs the calibration of the empirical data. Therefore, it is necessary to search empirical data with the method of data mining in the following work. In order to understand the influence of mental cost and instinct factors on consumers' purchase decision, the model of consumer utility should be further improved to understand the influence of mental cost and instinct factors on consumers' purchase decision deeply.

\section{REFERENCES}

[1] Kahneman, Daniel. Thinking, fast and slow. Macmillan, 2011.

[2] Mullainathan, Sendhil, and Eldar Shafir. Scarcity: Why having too little means so much. Macmillan, 2013.

[3] Loewenstein, George. "Out of control: Visceral influences on behavior." Organizational Behavior \& Human Decision Processes 65.3(1996):272292.

[4] Loewenstein, George, Drazen Prelec, and Catherine Shatto. "Hot/cold intrapersonal empathy gaps and the under-prediction of curiosity." Unpublished manuscript, Carnegie-Mellon University, Pittsburgh, PA (1998).

[5] Loewenstein, George, and Jennifer S. Lerner. "The role of affect in decision making." Handbook of affective science619.642 (2003): 3.

[6] Loewenstein, George. "Emotions in Economic Theory and Economic Behavior." American Economic Review 90.2(2000):426-432.

[7] Wilensky, U. NetLogo. http://ccl.northwestern.edu/netlogo/. Center for Connected Learning and Computer-Based Modeling, Northwestern University. Evanston, IL.1999 